\title{
Effects of Pergolide Mesilate on Metallothionein mRNAs Expression in a Mouse Model for Parkinson Disease
}

\author{
Shin-ichi Ono, ${ }^{*, a, b}$ Kohji HiRAI, ${ }^{a}$ and Ei-ichi ToKUdA ${ }^{a}$ \\ ${ }^{a}$ Research Unit of Clinical Pharmacy, College of Pharmacy, Nihon University; 7-7-1 Narashinodai, Funabashi, Chiba \\ 274-8555, Japan: and ${ }^{b}$ Division of Neurology, Akiru Municipal Medical Center; 85-1 Hikida, Akiruno, Tokyo 197-0136, \\ Japan. Received May 29, 2009; accepted July 13, 2009
}

\begin{abstract}
Dopamine agonists have neuroprotective properties in addition to their original pharmacologic function. We examined the effects of pergolide mesilate (PM) on the levels of metallothionein mRNA expression and lipid peroxidation in the corpus striata of 1-methyl 4-phenyl 1,2,3,6-tetrahydropyridine (MPTP)-induced Parkinsonian mice. Mice were administered normal saline (vehicle as a control), PM, or MPTP. A consecutive 7-d administration of MPTP via a gastric tube at a dose of $30 \mathrm{mg} / \mathrm{kg}$ significantly decreased metallothionein (MT)-I mRNA expression but did not influence MT-III mRNA expression. Lipid peroxidation, measured as the production of malondialdehyde reactive substances, did not increase after MPTP treatment. Although PM administration alone did not effect MT-I expression, an additional consecutive 7-d administration of PM (30 $\mu \mathrm{g} / \mathrm{kg})$ following MPTP treatment recovered the decreased MT-I level and increased MT-III expression. Lipid peroxidation was significantly suppressed. These results suggest that PM exerts an antioxidative property through the induction of MT-I and MT-III mRNAs simultaneously in response to cellular and/or tissue injury.
\end{abstract}

Key words metallothionein; neuroprotection; pergolide mesilate; 1-methyl 4-phenyl 1,2,3,6-tetrahydropyrdine; lipid peroxidation

Metallothionein (MT) is a family of low-molecular-weight, cysteine-rich, heat-stable, and metal-binding proteins. ${ }^{1,2}$ Four MT isoforms have been identified: MT-I, MT-II, MT-III, and MT-IV. MT-I and MT-II (MT-I/II) are ubiquitously expressed in all mammalian tissues including the CNS, whereas MT-III expression is limited to within the CNS, urethrogenital organs, and certain tumor cells. ${ }^{3-6)}$ MT-IV is executively expressed in stratified epithelia. ${ }^{7)}$ The essential physiological functions of MT-I/II isoforms are the detoxification of heavy metals such as cadmium and mercury, the homeostasis of essential metals such as zinc and copper, and antioxidant properties. ${ }^{1,2,8)}$ In view of the co-existence of MTIII and zinc ions in the CNS, the MT-III isoform is believed to be involved in zinc homeostasis. ${ }^{1-6,8)}$ Recently, another role, protection against critical tissue injury and tissue repair, has been proposed. ${ }^{9,10)}$ The significance of the MT-IV isoform has yet to be established.

Parkinson disease (PD) is a major neurodegenerative disease characterized by rest tremor, rigidity, bradykinesia, and postural instability caused by dopamine (DA) deficiency resulting from loss of the striatonigral dopaminergic (DAergic) neurons that originate at the substantia nigra pars compacta (SN) and terminate at the corpus striatum (CS) ${ }^{11)}$ Although its pathogenesis remains unknown, oxidative stress and apoptotic processes are thought to be involved, since the SN contains iron ions that provoke a form of oxidative stress known as Fenton-like reactions. ${ }^{12-14)}$ The supplementary administration of DA or dopamine agonists (DA agonists) is a reasonable pharmacological therapy in view of this pathology. However, therapeutic DA administration might facilitate DAergic neuronal death through the acceleration of Fentonlike reactions. ${ }^{14-16)}$ Recent advances have revealed that DA agonists have a neuroprotective function in addition to their original pharmacological properties. ${ }^{17-21)}$ However, ergotderived DA agonists such as pergolide mesilate (PM) may increase the risk of valvular heart diseases because of fibrosis. $^{22-24)}$ The clinical use of PM was, therefore, withdrawn in the United States but is still available in Japan, since the approved dose of PM is up to $1.25 \mathrm{mg} / \mathrm{d}$, which confers a relatively low risk for the development of valvular heart diseases.

Therefore, apart from the original pharmacological property, we examined the effects of PM on the mRNA expressions of MTs and lipid peroxidation in the CS to explore its essence of neuroprotective function from the antioxidative stand point of view in an animal model of PD produced by 1methyl 4-phenyl 1,2,3,6-tetrahydropyridine (MPTP). MPTP is an artificial narcotic agent and has been shown to exert a selective toxicity in the SN and to produce a PD-like disease in mammals as well as humans. ${ }^{25-27)}$ Consequently, MPTP is an established and popular agent for producing animal models of PD. ${ }^{28-33)}$

\section{MATERIALS AND METHODS}

Animals and Preparation of Rodent Model for PD by MPTP Treatment A total of 28 eight-week-old C57/6J mice were purchased from Sankyo Laboratory Service (Tokyo, Japan) and were used in the present study. The mice were kept under standard conditions: a 12-h on/off light cycle, a room temperature between $22^{\circ} \mathrm{C}$ and $25^{\circ} \mathrm{C}$, and food and water ad libitum. The mice were randomly assigned to one of the following four groups: 1) control (vehicle) group $(n=6)$, 2) PM group $(n=6), 3)$ MPTP group $(n=8)$, and 4) MPTP plus PM (MPTP+PM) group $(n=8)$. Each group of mice received a daily administration of normal saline (vehicle) or the following drugs via a gastric tube for seven consecutive days: control group, normal saline (vehicle); PM group, PM dissolved in normal saline at a dose of $30 \mu \mathrm{g} / \mathrm{kg}$ of body weight and adjusted to a final concentration of $1 \mu \mathrm{g} / \mathrm{ml}$; MPTP group, MPTP dissolved in normal saline at a dose of $30 \mathrm{mg} / \mathrm{kg}$ of body weight and adjusted to a final concentration of $1 \mathrm{mg} / \mathrm{ml}$. In the MPTP+PM group, the mice were given MPTP $(30 \mathrm{mg} / \mathrm{kg})$ for the first $7 \mathrm{~d}$. No treatment was given over the next $7 \mathrm{~d}$ to allow pathological changes to 
develop in DAergic neurons in the $\mathrm{CS}^{28-33)}$ Then, PM (30 $\mu \mathrm{g} / \mathrm{kg}$ ) was administered for seven consecutive days. All the mice were killed by decapitation under light ether anesthesia on the morning after the last normal saline (control group) or PM administration (PM and MPTP+PM groups $)^{17-21)}$ or $7 \mathrm{~d}$ after the last MPTP administration (MPTP group). ${ }^{28-33)}$ The whole brains were immediately removed, weighed, and placed on a glass plate over crushed ice; the corpus striata were then dissected. The ipsilateral sides were used for lipid peroxide (LPO) determination, and the other sides were preserved at $-80^{\circ} \mathrm{C}$ for subsequent mRNA isolation.

The present study was approved by the Ethical Committee for Laboratory Animal Use at the College of Pharmacy, Nihon University.

Confirmation of PD-Like Disease in MPTP-Treated Mice We confirmed the development of PD-like disease using kinesiological parameters as surrogate markers for a histological study. The horizontal and vertical motor activities of the mice were measured using an infrared beam test with Digiscan (Omnitech Electronics Inc., Columbus, $\mathrm{OH}$, U.S.A.) before and after drug(s) administration, as described previously. ${ }^{34,35)}$

Chemicals PM was purchased from Eli Lily Japan (Tokyo, Japan). Ethidium bromide, MPTP, and diethylpyrocarbonate (DEPC) were obtained from Sigma (St. Louis, MO, U.S.A.). The total RNA isolation reagent (TRIzol), Moloney murine leukemia virus reverse transcriptase, Thermus aquaticus DNA polymerase, oligo (dT) primer, dNTP ( $2^{\prime}$-deoxynucleotide 5'-triphosphate), DTT (dithiothreitol), $10 \times$ PCR buffer $(200 \mathrm{~mm}$ Tris- $\mathrm{HCl}$ [pH 8.0], and $500 \mathrm{~mm}$ $\mathrm{KCl}$ ), and electrophoretic-grade agarose were purchased from Invitrogen Life Technologies (Carlsbad, CA, U.S.A.).

MT Measurement MT levels were determined as mRNA expressions using a semi-quantitative reverse-transcription polymerase reaction (RT-PCR). Total RNA was isolated from the brain samples, and the following RT reactions were performed, as described previously. ${ }^{10,34)}$ The primers for mouse MT-I, MT-III, and glyceroaldehyde-3-phosphate (GAPDH) were obtained from Takara Bio (Gunma, Japan). The sequences of the primers were as follows: MT-I, 5'-ATG GAC CCC AAC TGT ATA GGA AGA CGC TGG-3' (forward) and 5'-GGG TGG AAC TGT ATA GGA AGA CGC TGG-3' (reverse); MT-III, 5'-ATG GAC CCT GAG ACC TGC CCC TGT CCT-3' (forward) and 5'-GGC CTC TGC CTT GGC CCC CTC TTC ACC-3' (reverse); and GAPDH, 5'-TAT TGG GCG CTT GGT CAC CA-3' (forward) and 5'CCA CCT TCT TGA TGT CAT CA-3' (reverse). ${ }^{10,34)}$ The predicted sizes of the amplified products (cDNA) were 260 bp for MT-I, 183 bp for MT-III, and 752 bp for GAPDH. ${ }^{10,34)}$

Detailed RT-PCR conditions for MT mRNAs have been described elsewhere. ${ }^{10,34)}$ Briefly, PCR was performed with denaturation at $94^{\circ} \mathrm{C}$ for $45 \mathrm{~s}$, annealing at $55^{\circ} \mathrm{C}$ for $30 \mathrm{~s}$, and extension at $72^{\circ} \mathrm{C}$ for $1.5 \mathrm{~min}$. The last extension was $10 \mathrm{~min}$. Within a logarithmic linear range, 18 cycles were used to determine the MT-I/GAPDH and MT-III/GAPDH ratios. ${ }^{10,34)}$ The cDNAs were electrophoresed on an agarose gel and visualized using ethidium bromide staining. The density of the cDNA bands was determined using Scion Image Software (Frederick, MD, U.S.A.). The relative amount of MT-I or MT-III mRNA standardized against the amount of
GAPDH mRNA was calculated.

LPO Measurement The LPO concentration was determined using the thiobarbituric acid (TBA) method, as described elsewhere. ${ }^{10,35,36)}$ Briefly, the brain samples were homogenized in ice-cold PBS. All subsequent steps were performed using amber-colored tubes. The homogenized samples were added to $40 \mathrm{~mm}$ sulfuric acid and $10 \%$ phosphotungstic acid and then centrifuged at $1500 \times \boldsymbol{g}$ for $10 \mathrm{~min}$. A TBA agent containing $8.8 \mathrm{M}$ acetic acid and $20 \mathrm{~mm}$ TBA was then added. The samples were incubated in a boiling bath for $1 \mathrm{~h}$. After cooling with tap water, $n$-butanol was added to extract the malondialdehyde, and the mixture was shaken vigorously by hand. After centrifugation at $1500 \times \boldsymbol{g}$ for $10 \mathrm{~min}$, the $n$-butanol phase was saved. The absorbance of the supernatant ( $n$-butanol-phase) was measured using a spectrofluorometer (FP-6200; Nihon Bunko, Tokyo, Japan) at an excitation wavelength of $515 \mathrm{~nm}$ and an emission wavelength of $553 \mathrm{~nm}$. The LPO level was estimated using 1,3,3-tetraetoxypropane as a reference standard. The results were expressed as nanomoles of malondialdehyde reactive substances per gram of wet tissue weight.

Data Analysis All the values were expressed as the mean \pm S.E.M. The serial activities and body weight changes within each group were assessed using a paired $t$-test or a repeated-measures ANOVA (analysis of variance). The activities and body weight at the start of the experiment (allocation), the brain weight, MT mRNA expression, and LPO levels among the four groups were analyzed using a one-way ANOVA. A Tukey's post hoc test was used if the ANOVA table produced a $p$ value $<0.05$.

\section{RESULTS}

Animal Activity A summary of the horizontal activities of the mice is shown in Fig. 1. The mice activities in all 4 groups tended to decrease after normal saline or drug treatment. However, only MPTP treatment (MPTP group and MPTP+PM group) significantly reduced the activity. In the MPTP + PM group, the additional 7-d administration of PM did not allow the activity level to recover, and it remained reduced (Fig. 1).

Body Weight Change and Brain Weight of Mice Serial body weight changes in the mice before and after drug(s) administration are shown in Fig. 2. No significant changes were observed. The brain weights in each group of mice are shown in Fig. 3. No significant difference in brain weight was found among the 4 groups after $\operatorname{drug}(\mathrm{s})$ administration.

Expression of MT-I and MT-III mRNAs in the Corpus Striatum The expressions of MT-I and MT-III mRNAs are shown in Figs. 4 and 5, respectively. MT-I mRNA expression decreased significantly after MPTP treatment. The decrease returned to the control level after the additional 7-d administration of PM. Interestingly, PM administration alone did not influence MT-I mRNA expression (Fig. 4).

MT-III mRNA expression did not change after PM administration alone or MPTP treatment alone; However the 7-d PM treatment following MPTP administration significantly upregulated the MT-III level (Fig. 5).

Concentration of LPO in the Corpus Striatum The LPO level in the CS is shown in Fig. 6. PM administration alone decreased LPO level, however not significant. PM ad- 


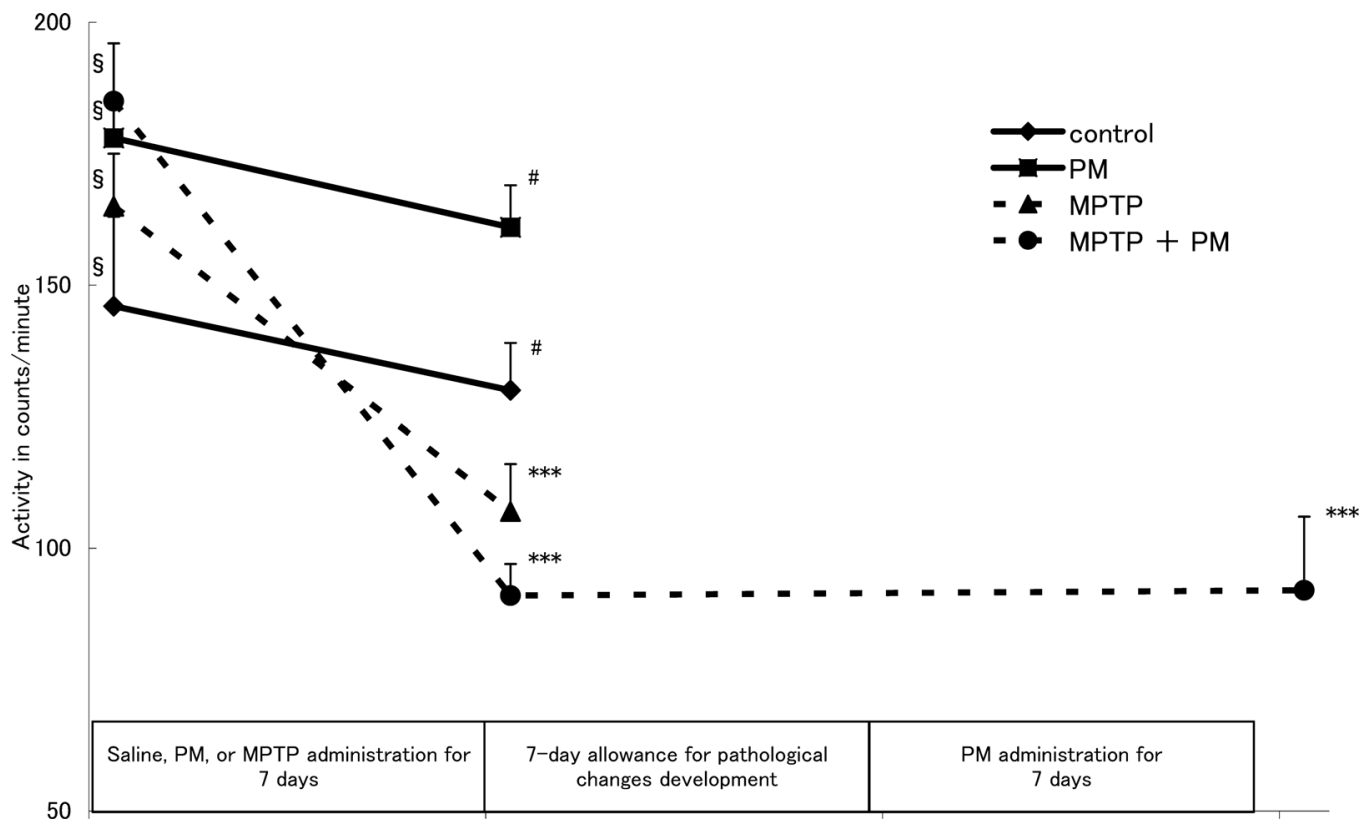

Fig. 1. Horizontal Motor Activities of Mice

No significant difference in motor activities was observed among the 4 groups at the time of group allocation ( $\S, p=0.135$ using a one-way ANOVA). No significant decrease in activities was detected in the control group or the PM group after administration, according to a paired $t$-test ( $\# p=0.186$ and $p=0.159$, respectively). The activities were significantly decreased after MPTP treatment for 7 consecutive days $\left(* * * p=1.01 \times 10^{-4}\right.$ using a paired $t$-test in the MPTP group and $p=2.40 \times 10^{-4}$ using a repeated measures ANOVA in the MPTP+PM group). Additional treatment with PM for $7 \mathrm{~d}$ did not enable the decreased activity in the MPTP+PM group to recover (***). PM, pergolide mesilate; MPTP, 1methyl 4-phenyl 1,2,3,6-tetrahydropyridine. $n=6$ in control group and PM group, $n=8$ in MPTP group and MPTP plus PM group.

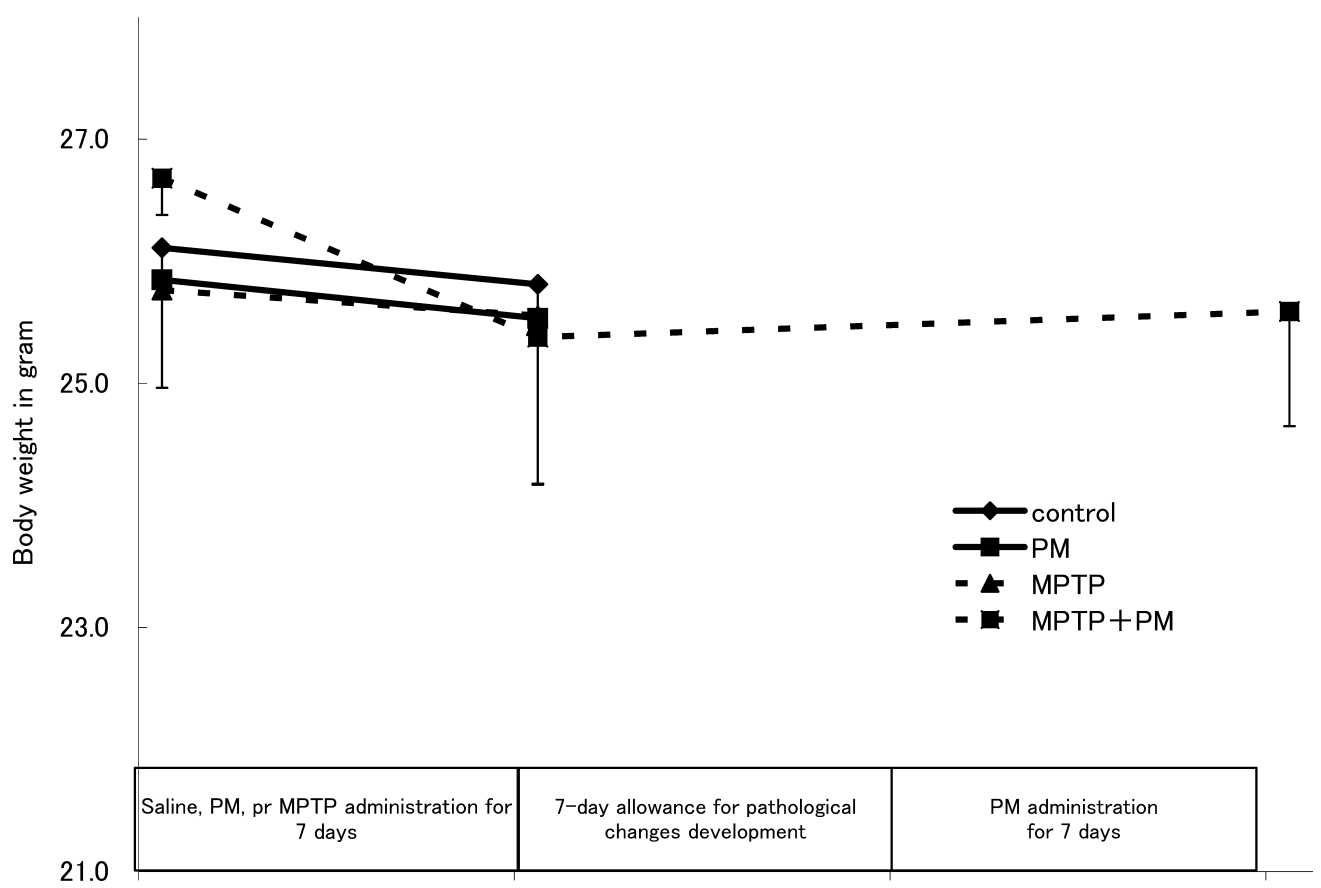

Fig. 2. Body Weight Change

At allocation, no significant differences in body weight were observed among the 4 groups ( $p=0.247$ using a one-way ANOVA). No significant serial body weight changes were observed after any of the treatments in the present study ( $p=0.331$ for control, $p=0.346$ for PM group, $p=0.609$ for MPTP group using a paired $t$-test, and $p=0.552$ for MPTP+PM group using a repeated measures ANOVA). PM, pergolide mesilate; MPTP, 1-methyl 4-phenyl 1,2,3,6-tetrahydropyridine. $n=6$ in control group and PM group, $n=8$ in MPTP group and MPTP plus PM group.

ministration following MPTP treatment significantly suppressed LPO formation (Fig. 6).

\section{DISCUSSION}

In the present study, we confirmed the development of PD- like disease based on the motor activities of the mice (Fig. 1). The administration of $30 \mathrm{mg} / \mathrm{kg}$ of PM for 3-to-5 consecutive days has been pathologically confirmed to result in the development of PD-like disease. ${ }^{28-33,37,38)}$ Gastric tube stimulation might uniformly decrease the motor activities in the 4 groups. However, in view of the significant decrease in the 


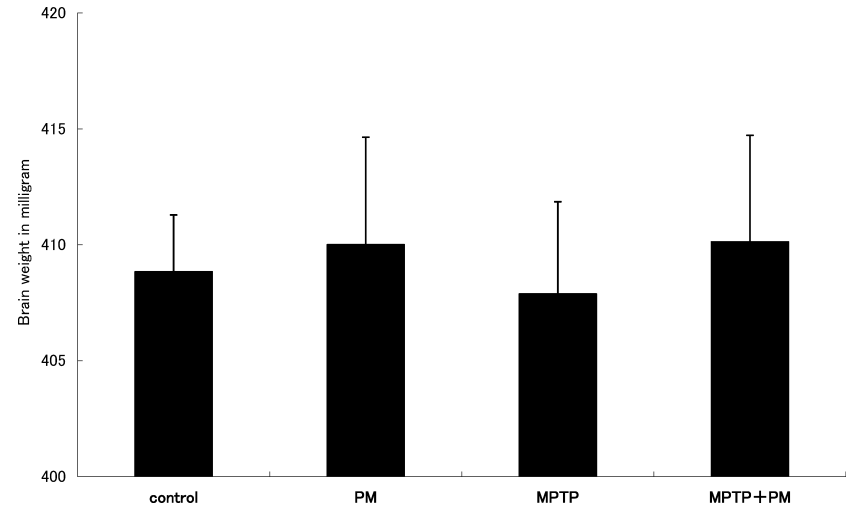

Fig. 3. Brain Weight Differences

No differences in whole brain weight were observed among the 4 groups ( $p=0.975$ using a one-way ANOVA). $n=6$ in control group and PM group, $n=8$ in MPTP group and MPTP plus PM group.

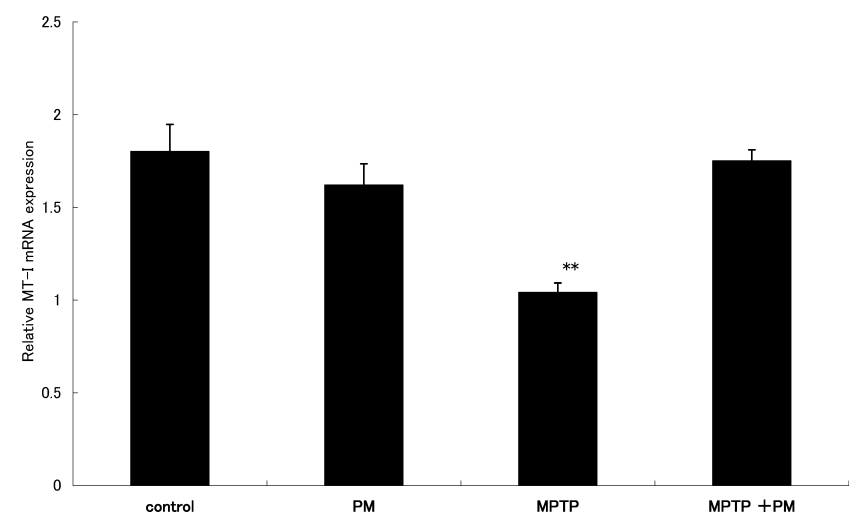

Fig. 4. Metallothionein-I Isoform mRNA Expression in the Corpus Striatum

MT-I expression decreased significantly after MPTP administration at a dose of $30 \mathrm{mg} / \mathrm{kg}$ of body weight for 7 consecutive days ( $* * p=5.37 \times 10^{-5}$ using a one-way ANOVA and $p<0.01 v s$. control using a Tukey's post hoc test). This decrease recovered to the same level as the control after an additional 7-d administration of PM (30 $\mu \mathrm{g} / \mathrm{kg})$ following MPTP treatment (MPTP+PM group). PM administration alone did not influence MT-I mRNA expression. PM, pergolide mesilate; MPTP, 1-methyl 4-phenyl 1,2,3,6-tetrahydropyridine. $n=6$ in control group and PM group, $n=8$ in MPTP group and MPTP plus PM group.

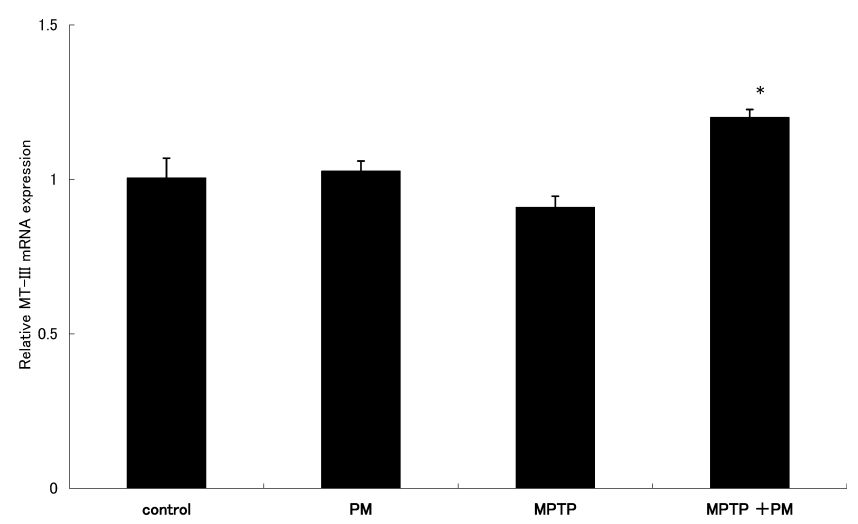

Fig. 5. Metallothionein-III Isoform mRNA Expression in the Corpus Striatum

MT-III expression was not influenced by PM treatment alone or MPTP administration alone; however PM administration after MPTP treatment (MPTP+PM group) significantly upregulated MT-III level $\left(* p=6.63 \times 10^{-5}\right.$ using a one-way ANOVA and $p<0.05$ vs. control using a Tukey's post hoc test). PM, pergolide mesilate; MPTP, 1 methyl 4-phenyl 1,2,3,6-tetrahydropyridine. $n=6$ in control group and PM group, $n=8$ in MPTP group and MPTP plus PM group.

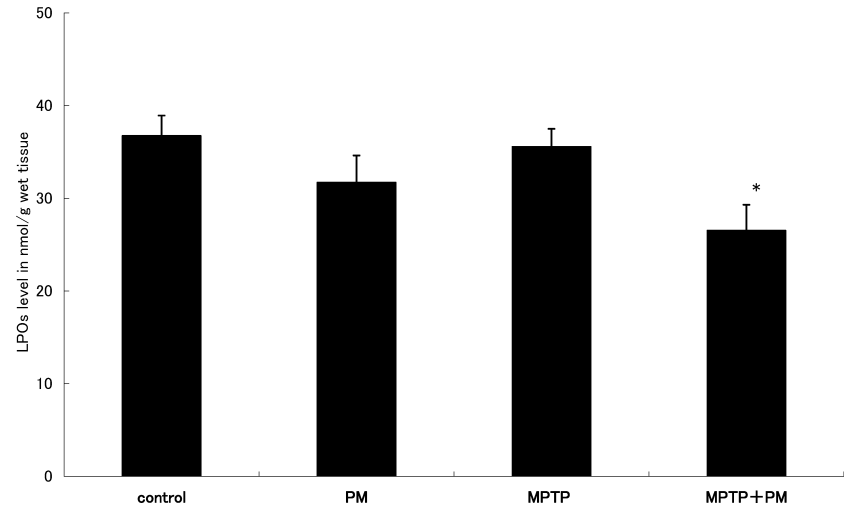

Fig. 6. Lipid Peroxides Level in the Corpus Striatum

The lipid peroxide (LPO) level, which was assessed by measuring malondialdehyde reactive substances, was slightly decreased by $\mathrm{PM}$ alone administration, and was significantly $(* p=0.040$ using a one-way ANOVA and $p<0.05 v s$. control using a Tukey's post hoc test) suppressed after PM administration following MPTP treatment. PM, pergolide mesilate; MPTP, 1-methyl 4-phenyl 1,2,3,6-tetrahydropyridine. $n=6$ in control group and PM group, $n=8$ in MPTP group and MPTP plus PM group.

motor activities in the MPTP-treated groups (MPTP group and MPTP + PM group) after the administration of MPTP for 7 consecutive days, we concluded and proposed that the measurement of motor activities is a useful surrogate parameter for confirming the development of PD-like disease. Additional treatment with PM after MPTP administration (MPTP+PM group) failed to allow the decreased activities to recover (Fig. 1). DA agonists produce clinical improvements more slowly than DAs. Seven days of PM treatment was probably too short to restore the striatonigral damage induced by MPTP.

MPTP administration has been shown to reduce the DA concentration $^{28-33)}$ and the glutathione (GSH) level ${ }^{37)}$ and to increase LPO formation in the striatonigral pathway. ${ }^{38)}$ MPTP is converted to the toxic agent $\mathrm{MPP}^{+}$(1-methyl-4phenylpyridium) by MAO-B (type B monoamine oxidase). Specific uptake of $\mathrm{MPP}^{+}$into the striatonigral DAergic neurons is the nature of MPTP toxicity. ${ }^{25-27,29,38)}$ DA agonists have a neuroprotective function in addition to their original pharmacological properties, ${ }^{17-21)}$ and the nature of this neuroprotection is likely antioxidative, ${ }^{18,39-44)}$ antiischemic, ${ }^{20)}$ antiapoptotic, ${ }^{45)}$ and antiaging. ${ }^{46)}$ The protective functions of $\mathrm{PM}$, an ergot-derived DA agonist, were investigated in view of its effects on the suppression of oxygen-derived radical generation and the preservation of antioxidants in rodent PD models $^{18,39-41,43)}$ as well as in vitro studies. ${ }^{42)}$ In humans, the serum catalase and superoxide dismutase (SOD) activities were enhanced and the GSH level was increased with the addition of PM to DA, compared with DA alone. ${ }^{44)}$ Although MT-I has antioxidative properties ${ }^{1,2,8)}$ and MT-III might be associated with tissue repair, ${ }^{9,10)}$ the effects of PM on MT induction have not been reported.

A decrease in MT-I mRNA expression after MPTP treatment was previously shown. ${ }^{47)}$ In the present study, we showed that the administration of PM following MPTP treatment allowed the decreased MT-I level to recover and inhibited the increase in LPO (Figs. 4, 6), suggesting that PM works as an antioxidant via MT-I induction. MT-I is shown to attenuate peroxynitrite-induced oxidative stress ${ }^{48)}$ and quinine-induced dopaminergic toxicity. ${ }^{49)}$ The administration of MT-I inducers, copper ions, cadmium ions, and dexametha- 
zone suppressed LPO production ${ }^{50)}$ and inhibited MPTP-induced reductions in DA. ${ }^{31)}$ The inducibility of MT-I after PM administration has not been reported previously. Of note, PM administration alone did not induce MT-I or MT-III expression (Figs. 4, 5). The induction of MT-I by PM may require the striatonigral pathway to be injured and/or DA to be depleted to some extent. However, another possibility is that LPO suppression is independent of MTs. Previous studies have shown a suppression in nitric oxide radical and hydroxyl radical generation ${ }^{42,43)}$ and increases in superoxide dismutase $^{39-41)}$ and catalase ${ }^{44)}$ activities after PM treatment. The LPO suppression in the present study might be associated with these changes.

We also found that MT-III mRNA expression was not influenced by and was resistant to MPTP treatment. MT-III mRNA was significantly upregulated in the MPTP+PM group (Fig. 5). The MT-III isoform is supposed to serve a role in tissue repair and protection against critical tissue injury ${ }^{9,10,34)}$ as well as in zinc storage. ${ }^{3-6)}$ Taking these aspects into account, the resistance to MPTP treatment and the tendency toward upregulation after PM administration following MPTP treatment seem reasonable and acceptable. MT-III might play a broad defensive role, not limited to oxidative stress, in tissue repair and protection against critical tissue injury, in cooperation with MT-I.

Although additional treatment with PM after MPTP administration (MPTP + PM group) failed to recover motor activities (Fig. 1), in view of endogenous antioxidative property, the 7-d PM treatment is enough to induce MT-I and MTIII, and suppress LPO formation in the CS.

\section{REFERENCES}

1) Aschner M., Cherian M. G., Klaassen C. D., Palmiter R. D., Erickson J. C., Bush A. I., Toxicol. Appl. Pharmacol., 142, 229-242 (1997).

2) Hidalgo J., Aschner M., Zatta P., Vasák M., Brain Res. Bull., 55, 133145 (2001)

3) Uchida Y., Takio K., Titani K., Ihara Y., Tomonaga M., Neuron, 7, 337-347 (1991).

4) Hoey J. G., Garrett S. H., Sens M. A., Todd J. H., Sens D. A., Toxicol. Lett., 92, 149-160 (1997).

5) Garrett S. H., Sens M. A., Todd J. H., Somji S., Sens D. A., Toxicol. Lett., 105, 207-214 (1999).

6) Sens M. A., Somji S., Garrett S. H., Beall C. L., Sens D. A., Am. J. Pathol., 159, 21-26 (2001).

7) Quaife C. J., Findley S. D., Erickson J. C., Froelick G. J., Kelly E. J., Zambrowicz B. P., Palmiter R. D., Biochemistry, 33, 7250-7259 (1994).

8) Kägi J. H. R., "Metallothionein III. Biological Roles and Medical Implications," ed. by Suzuki K. T., Imura N., Kimura M., Birkhauser Verlag, Boston, 1993, pp. 29-55.

9) Hozumi I., Inuzuka T., Hiraiwa M., Uchida Y., Anezaki T., Ishiguro H., Kobayashi H., Uda Y., Miyatake T., Tsuji S., Brain Res., 688, 143-148 (1995).

10) Ono S. I., Ishizaki Y., Tokuda E., Tabata K., Asami S., Suzuki T., Biol. Trace Elem. Res., 115, 147-156 (2007).

11) Fahn S., "Merritt's Textbook of Neurology," 9th ed., ed. by Rowland L. P., Williams and Wilkins, Philadelphia, 1995, pp. 713-730.

12) Dauer W., Przedborski S., Neuron, 39, 889-909 (2003).

13) Beal M. F., Ann. Neurol., 53, S39-S48 (2003).

14) Siderowf A., Stern M., Ann. Intern. Med., 138, 651—658 (2003).
15) Fahn S., Oakes D., Shoulson I., Kieburtz K., Rudolph A., Lang A., Olanow C. W., Tanner C., Marek K., N. Engl. J. Med., 351, 24982508 (2004).

16) Fahn S., the Parkinson Study Group, J. Neurol., 252 IV37-IV42, (2005).

17) Lange K. W., Rausch W. D., Gsell W., Naumann M., Oestreicher E., Riedere P., J. Neural Transm. Suppl., 43, 183-201 (1994).

18) Asanuma M., Ogawa N., Nishibayashi S., Kawai M., Kondo Y., Iwata E., Arch. Int. Pharmacodyn. Ther, 329, 221-229 (1995).

19) Yamamoto M., Neurology, 51, S10 - S12 (1998).

20) O’Neill M. J., Hicks C. A., Ward M. A., Cardwell G. P., Reymann J.M., Allain H., Bentué-Ferrer D., Eur. J. Pharmacol., 352, 37-46 (1998).

21) Le W.-D., Jankovic J., Drugs Aging, 18, 389-396 (2001)

22) van Camp G., Flamez A., Cosyns B., Weytiens C., Muyldermans L., van Zandijcke M., de Sutter J., Santens P., Decoodt P., Moerman C., Schoors D., Lancet, 363, 1179-1183 (2004).

23) Schade R., Andersohn F., Suissa S., Haverkamp W., Garbe E., N. Engl. J. Med., 356, 29-38 (2007).

24) Zanettini R., Antonini A., Gatto G., Gentile R., Tesei S., Pezzoli G., $N$. Engl. J. Med., 356, 39-46 (2007).

25) Langston J. W., Ballard P., Tetrud J. W., Irwin I., Science, 219, 979980 (1983)

26) Langston J. W., Ballard P. A. Jr., N. Engl. J. Med., 309, 310 (1983).

27) Langston J. W., Langston E. B., Irwin I., Acta Neurol. Scand. Suppl., 100, 49-54 (1984)

28) Heikkila R. E., Cabbat F. S., Manzino L., Duvoisin R. C., Neuropharmacology, 23, 711-713 (1984).

29) Gerlach M., Riederer P., Przuntek H., Youdim M. B. H., Eur. J. Pharmacol., 208, 273-286 (1991).

30) Rios C., Alvarez-Vega R., Rojas P., Pharmacol. Toxicol., 76, 348-352 (1995).

31) Rojas P., Rịos C., Neurochem. Res., 22, 17-22 (1997).

32) Rojas P., Klaassen C. D., Neurosci. Lett., 273, $113-116$ (1999).

33) Rojas P., Rojas-Castaňeda J., Vigueras R. M., Habeebu S. S., Rojas C., Rịos C., Ebadi M., Neurochem. Res., 25, 503-509 (2000).

34) Ono S. I., Endo Y., Tokuda E., Tabata K., Asami S., Ito Y., Suzuki T., Biol. Trace Elem. Res., 113, 93-103 (2007).

35) Tokuda E., Ono S. I., Ishige K., Naganuma A., Ito Y., Suzuki T., Toxicology, 229, 33-41 (2007).

36) Ono S. I., Cai L., Cherian M. G., Radiat. Res., 150, 52-57 (1998).

37) Ferraro T. N., Golden G. T., DeMattei M., Hare T. A., Fariello R. G., Neuropharmacology, 25, 1071-1074 (1986).

38) Rojas P., Rios C., Pharmacol. Toxicol., 72, 364-368 (1993).

39) Clow A., Hussain T., Glover V., Sandler M., Walker M., Dexter D., J. Neural Transm. Gen. Sect., 90, 27-31 (1992).

40) Clow A., Freestone C., Lewis E., Dexter D., Sandler M., Glover V., Neurosci. Lett., 164, 41-43 (1993).

41) Glover V., Clow A., Sandler M., J. Neural Transm. Suppl., 40, 37-45 (1993).

42) Nishibayashi S., Asanuma M., Kohno M., Gómez-Vargas M., Ogawa N., J. Neurochem., 67, 2208-2211 (1996).

43) Gómez-Vargas M., Nishibayashi-Asanuma S., Asanuma M., Kondo Y., Iwata E., Ogawa N., Brain Res., 790, 202-208 (1998).

44) Chalimoniuk M., Stepien A., Stroszajder J. B., Clin. Neuropharmacol., 27, 223-229 (2004).

45) Ebadi M., Brown-Borg H., Refaey H. E., Singh B. B., Garrett S., Shavali S., Sharma S. K., Brain Res. Mol. Brain Res., 134, 67-75 (2005).

46) Felten D. L., Felten S. Y., Fuller R. W., Romano T. D., Smalstig E. B., Wong D. T., Clemens J. A., Neurobiol. Aging, 13, 339-351 (1992).

47) Rojas P., Hidalgo J., Ebadi M., Rios C., Prog. Neuropsychopharmacol. Biol. Psychitary, 24, 143-154 (2000).

48) Ebadi M., Sharma S., Exp. Biol. Med., 231, 1576-1583 (2006).

49) Miyazaki I., Asanuma M., Hozumi H., Miyoshi K., Sogawa N., FEBS Lett., 581, 5003-5008 (2007).

50) Alcaraz-Zubeldia M., Rojas P., Boll C., Ríos C., Neurochem. Res., 26, 59-64 (2001). 